\title{
Analyzing vegetation dynamic trend on the Mongolian Plateau based on the Hurst exponent and influencing factors from 1982-2013
}

\author{
TONG Siqin ${ }^{1,2,3}$, * ${ }^{2}$ HANG Jiquan ${ }^{1,2}$, BAO Yuhai ${ }^{3,4}$, LAI Quan ${ }^{1,3,4}$, LIAN Xiao, \\ LI Na ${ }^{1}$, BAO Yongbin ${ }^{1}$ \\ 1. School of Environment, Northeast Normal University, Changchun 130024, China; \\ 2. Key Laboratory for Vegetation Ecology, Ministry of Education, Changchun 130024, China; \\ 3. College of Geography, Inner Mongolia Normal University, Hohhot 010022, China; \\ 4. Inner Mongolia Key Laboratory of Remote Sensing and Geographic Information Systems, Inner Mongolia \\ Normal University, Hohhot 010022, China; \\ 5. Graduate School of Life and Environmental Sciences, Tsukuba University, Ibaraki 305, Japan
}

\begin{abstract}
This study analyzed the spatial and temporal variations in the Normalized Difference Vegetation Index (NDVI) on the Mongolian Plateau from 1982-2013 using Global Inventory Modeling and Mapping Studies (GIMMS) NDVI3g data and explored the effects of climate factors and human activities on vegetation. The results indicate that NDVI has slight upward trend in the Mongolian Plateau over the last 32 years. The area in which NDVI increased was much larger than that in which it decreased. Increased NDVI was primarily distributed in the southern part of the plateau, especially in the agro-pastoral ecotone of Inner Mongolia. Improvement in the vegetative cover is predicted for a larger area compared to that in which degradation is predicted based on Hurst exponent analysis. The NDVI-indicated vegetation growth in the Mongolian Plateau is a combined result of climate variations and human activities. Specifically, the precipitation has been the dominant factor and the recent human effort in protecting the ecological environments has left readily detectable imprints in the NDVI data series.
\end{abstract}

Keywords: remote sensing; GIMMS NDVI3g; vegetation dynamic trend; Hurst exponent; residual trend analysis; Mongolian Plateau

\section{Introduction}

The Fourth Assessment Report of the Intergovernmental Panel on Climate Change (IPCC) indicated that there has been a consistent increase in global temperatures for the past decade

Received: 2017-04-01 Accepted: 2017-09-28

Foundation: National Key Technology R\&D Program of China, No.2013BAK05B01, No.2013BAK05B02; National Natural Science Foundation of China, No.41571491, No.61631011; The Program of Introducing Talents of Discipline to Universities, No.B16011

Author: Tong Siqin (1991-), PhD, specialized in vegetation dynamic change, long-term climate change, remote sensing and GIS. E-mail: tongsq223@nenu.edu.cn

"Corresponding author: Zhang Jiquan (1965-), Professor, E-mail: zhangjq022@nenu.edu.cn 
(Zhao et al., 2007). Global warming is expected to bring about a series of serious environmental and social problems, including droughts, water shortages, and species extinction. These problems are most apparent in sensitive areas, especially arid zones such as the Sahel of Africa or the ecotones of China, North America, and Australia, all of which face the challenges of desertification, food insecurity, and changing land ecology (Hulme et al., 2001; Zhao and Qiu, 2001; Seager et al., 2007; Whetton et al., 1993). Furthermore, the vulnerability and instability of arid and semi-arid regions makes them particularly sensitive to climate change through desertification, soil erosion, and other regional degradation problems (Li et al., 2006).

Climate change in arid and semi-arid regions is therefore an important aspect of global climate change research. Changes in these regions have unique characteristics besides their consistency with global climate change. For example, the Mongolian Plateau is an area sensitive to global warming (Wang et al., 2008): temperature increases on the Mongolian Plateau have been faster than the global or regional warming rates. As this plateau is in an arid and semi-arid region, the primary biome is grassland and the eco-system is fragile. Temperatures in the Mongolian Plateau have increased significantly over the past 40 years (Li et al., 2006), while decreased rainfall has aggravated drought conditions (Yatagai and Yasunari, 1995; Li and Liu, 2012). Desertification of the region has become an issue due to the simultaneous influence of climate change and human activity (Zhuo, 2007). The former impacts the vegetation environment, thus influencing vegetation growth. As a link between the soil, atmospheric, and water systems, vegetation cover can thus be used as an indicator for global climate change (Lambin and Strahler, 1994; Liu et al., 2006). Therefore, the study of vegetation changes and influencing factors on the Mongolian Plateau is important for planning sustainable development and understanding global climate change.

Remote sensing technology is an important method for studying a wide range of regional and global ecosystems. The Normalized Difference Vegetation Index (NDVI), a remote sensing product, provides a convenient method for displaying vegetation distribution and changes. Recently, changes in local NDVI and its relationship with climate change have become a focus of global climate change research (Ichii et al., 2012; Park and Sohn, 2010; Song and Ma, 2011; Piao et al., 2006). The Global Inventory Modeling and Mapping Studies (GIMMS) NDVI dataset is widely used to monitor changes in vegetation cover at regional and global scales because of its high temporal resolution, long time-series, and high data quality (Ichii et al., 2002; Song and Ma, 2011; Piao et al., 2006; Nemani et al., 2003; Jong et al., 2011).

Environmental problems on the Mongolian Plateau have become increasingly serious in recent years; however, previous studies on vegetation cover in this region have mainly focused on the response of vegetation to climate change (Zhang et al., 2009; Zhao et al., 2015; Miao et al., 2015; John et al., 2013). However, vegetation cover is affected by both climate change and human activity; the rapid expansion and intensity of human activities has already produced significant impacts on vegetation. Previous research has considered climate change almost exclusively, mostly ignoring the effects of human activity on land use and vegetation cover changes, has limited our understanding of changes in vegetation cover. Therefore, in this study we used 32 years of NDVI data (1982-2013) from the Advanced Very High Resolution Radiometer (AVHRR) in combination with Sen's slope, Pearson cor- 
relation analysis, and residual trend analysis to determine changes in the vegetation cover on the Mongolian Plateau and to identify the effects of climate and human activities on vegetation changes. We also conducted an R/S analysis using the Hurst exponent to predict future trends in vegetation dynamics on the plateau. This study will assist decision makers in formulating relevant laws and policies and improve the overall understanding of regional and global climate and environmental changes.

\section{Data and methods}

\subsection{Study area}

The Mongolian Plateau is located in the interior of the Eurasian continent, spanning Mongolia, southern Russia, and northern China (Wei et al., 2009). In this study, we chose the central region of the Mongolian Plateau (referred to hereafter simply as the Mongolian Plateau) as the study area, covering all of Mongolia and Inner Mongolia, from $37^{\circ} 22^{\prime}$ to $53^{\circ} 20^{\prime} \mathrm{N}$ and $87^{\circ} 43^{\prime}$ to $126^{\circ} 04^{\prime} \mathrm{E}$, with a total area of $275 \times 10^{4} \mathrm{~km}^{2}$. The terrain is generally mountainous in the northwest, while the Gobi desert covers the southwestern section. The central and eastern parts of the plateau are relatively flat and covered in hilly grassland. The elevation decreases gradually across the plateau from west to east, with an average elevation of about $1580 \mathrm{~m}$ (Figure 1a). Due to the gradual changing climate, vegetation types in the region shift from forest to steppe to desert from east to west (Figure 1b). Precipitation in the northern plateau is brought by polar air masses originating in the Arctic Ocean, while that in the
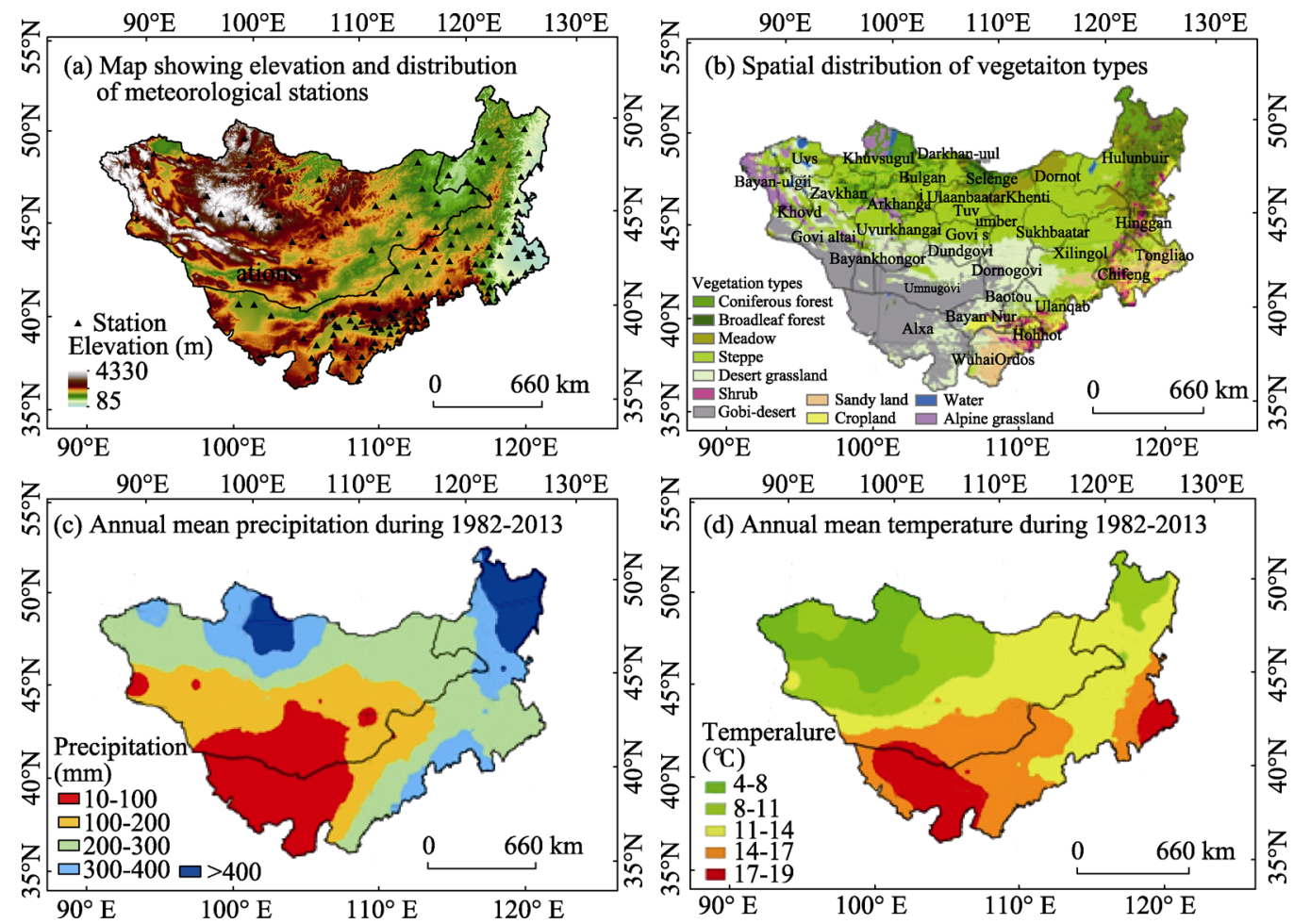

Figure 1 Geographic characteristics of the Mongolian Plateau: Elevation (a), vegetation types (b), annual mean precipitation (c), and temperature (d) 
southern plateau is brought by tropical air masses originating in the Pacific Ocean. Rainfall ranges from $300 \mathrm{~mm}$ in the north to $100 \mathrm{~mm}$ in the south (Figure 1c). At the same time, temperatures are lower in the north than in the south (Figure 1d).

\subsection{Data sources}

The GIMMS NDVI3g data have a spatial resolution of $8 \mathrm{~km}$ and a temporal resolution of 15 days. Monthly NDVI data were obtained from 1982-2013 using the maximum value composite (MVC) method, which eliminates the effects of solar elevation angle, cloud cover, and atmospheric interference (Holben, 1986). Since vegetation in most parts of the Mongolian Plateau shows minimal growth in winter (or is covered by snow), the growing season (April to October) was selected for this study. In the Gobi desert area, observations are affected by the ground surface, making them unreliable for describing the actual vegetation cover. Therefore, in areas with low vegetation cover or desert biomes, the annual or monthly average NDVI value serves as a threshold to exclude non-vegetation factors. An average NDVI value of 0.05 was used as the threshold in earlier studies (Myneni et al., 1997) but an annual mean of 0.1 has been used as the threshold value in more recent studies (Zhou et al., 2001; Zhou et al., 2003). For this study, any areas with NDVI values less than 0.1 were defined as "non-vegetation"; these areas were largely distributed in the desert area of the western plateau (Figure 2).

Monthly mean temperatures and monthly precipitation data were provided by the Inner Mongolia Key Laboratory of Remote Sensing and Geographic Information Systems. Observations were collected at 170 meteorological stations (129 in Inner Mongolia and 60 in Mongolia, Figure 1a) across the plateau. Using the station locations, the observations were then interpolated monthly at the same resolution as the NDVI to obtain spatio-temporal distributions of temperature and precipitation.

\subsection{Methods}

\subsubsection{Sen's slope}

The Sen's slope estimator was used to analyze dynamic trends in NDVI. The median value of the slope series is used as the basis for determining trend, which can help reduce the influence of missing or abnormal data (Sen, 1968; Fensholt et al., 2012). The calculation of slope was as follows:

$$
\text { Slope }=\text { Median }\left[\frac{\left(x_{j}-x_{i}\right)}{(j-i)}\right], \forall j>i
$$

where $x_{i}$ and $x_{j}$ are the sequence values at times $i$ and $j$, respectively, and $1 \leqslant i<j \leqslant n, \mathrm{n}$ being the sequence length, i.e., the number of years in the study period. An upward trend is indicated with slope $>0$ and a downward trend is indicated with slope $<0$. The significance of the trend was assessed using the Mann-Kendall non-parametric statistical test.

\subsubsection{Mann-Kendall test}

The Mann-Kendall statistical test (MK) is a non-distribution test (non-parametric statistical test) (Kendall, 1975; Tošić, 2004) in which the data do not need to be in a particular order and are not affected by outliers. For the sequence $X_{i}=\left(x_{1}, x_{2}, \cdots, x_{n}\right)$, the size relation of $x_{i}$ and 
$x_{j}$ in allomorph $\left(x_{i}, x_{j}, j>i\right)$ is first determined and set as $\mathrm{S}$. The test hypotheses are $\mathrm{H}_{0}$ (the data in the sequences are randomly arranged, i.e. there is no significant trend) and $\mathrm{H}_{1}$ (the sequence has a monotonic tendency upward or downward). The test statistic $S$ was calculated using Equations 2 and 3:

$$
\begin{gathered}
S=\sum_{i=1}^{n-1} \sum_{j=i+1}^{n} \operatorname{sgn}\left(x_{j}-x_{i}\right) \\
\operatorname{sgn}\left(x_{j}-x_{i}\right)=\left\{\begin{array}{r}
+1, x_{j}-x_{i}>0 \\
0, x_{j}-x_{i}=0 \\
-1, x_{j}-x_{i}<0
\end{array}\right.
\end{gathered}
$$

When $n \geqslant 10$, the statistic $S$ approximates the standard normal distribution and the Z-value (Equation 4) can be used to test the trend:

$$
Z=\left\{\begin{array}{r}
\frac{S-1}{\sqrt{\operatorname{VAR}(S)}}, S>0 \\
0, S=0 \\
\frac{S+1}{\sqrt{\operatorname{VAR}(S)}}, S<0
\end{array}\right.
$$

where $\operatorname{VAR}(S)=\left(n(n-1)(2 n+5)-\sum_{i=1}^{m} t_{i}\left(t_{i}-1\right)\left(2 t_{i}+5\right)\right) / 18, n$ is the number of data points in the sequence, $m$ is the number of repeated datasets in the sequence, and $t_{i}$ is the number of repeated data values in the $i$ th group. At the given significance level, $\alpha=0.05$, the threshold of the normal distribution is $Z_{1-a / 2}$. When $|Z| \leqslant Z_{1-a / 2}$, the null hypothesis can be accepted (the trend is insignificant), and when $|Z|>Z_{1-a / 2}$, the null hypothesis is rejected and the trend is significant, $Z_{1-a / 2}=Z_{0.975}=1.96$.

\subsubsection{Hurst exponent and $\mathrm{R} / \mathrm{S}$ analysis}

$\mathrm{R} / \mathrm{S}$ analysis was first proposed by Hurst (1951) in the analysis of hydrological data for the Nile, and is often used to analyze long-term time-series correlations. The principle of R/S is briefly described as follows (Granero et al., 2008):

A time series $x(t)$ is defined as:

$$
\langle x\rangle_{t}=\frac{1}{\tau} \sum_{t=1}^{\tau} x(t) \quad t=1,2,3 \cdots
$$

The cumulative deviation is calculated as:

$$
x(t, \tau)=\sum_{u=1}^{\tau}\left(x(u)-\langle x\rangle_{t}\right) 1 \leqslant t \leqslant \tau
$$

The extreme deviation sequence is calculated as:

$$
R(\tau)=\max _{1 s t s \tau} X(t, \tau)-\min _{1 s t s \tau} X(t, \tau) \quad \tau=1,2,3 \cdots
$$

The standard deviation sequence is calculated as:

$$
S(\tau)=\left[\frac{1}{\tau} \sum_{t=1}^{\tau}(x(t)-\langle x\rangle \tau)^{2}\right]^{\frac{1}{2}} \quad \tau=1,2,3 \cdots
$$


Taking the ratio of $R(\tau)$ and $S(\tau)$, we arrive at:

And assume that:

$$
R / S=R(\tau) / S(\tau)
$$

$$
R / S \propto\left(\frac{\tau}{2}\right)^{H}
$$

The Hurst phenomenon exists in the time series, such that $\mathrm{H}$ is called the Hurst exponent with a range from 0 to 1 . When $\mathrm{H}=0.5$, there is no change in the data. When $\mathrm{H}>0.5$, the process has a continuous characteristic and the future trend is consistent with the past. When $\mathrm{H}<0.5$, the future trend is expected to be reversed from the past trend. We also used the Pearson correlation (Chang et al., 2014) and residual trend analysis (Wessels et al., 2007) to study the relationships of vegetation with climate factors and human activities, respectively.

\section{Results}

\subsection{Spatio-temporal variations in NDVI on the Mongolian Plateau from 1982-2013}

\subsubsection{Temporal variations in NDVI}

The spatial pattern of annual average NDVI during the study period (Figure 2) shows that the vegetation cover is generally low to the west and high to the east, which is consistent with the desert-grassland-forest distribution shown in Figure 1. The greatest vegetation cover in Mongolia is located in the north and east, while the southwest is relatively desolate. In Inner Mongolia, the greatest vegetation cover is mainly distributed in the north, while the west is a desert area with poor vegetation cover.

Figure 3 shows the annual NDVI trends for Inner Mongolia, Mongolia, and the entire Mongolian Plateau during the study period. The NDVI trends in Inner Mongolia and Mongolia are consistent with those of the entire Mongolian Plateau over the past 32 years, showing a slight upward trend with a rate of $0.0003 / y r$. This may be related to a general increase in global temperature, especially at the middle and high latitudes (Parry et al., 2007). At high latitudes and altitudes (where

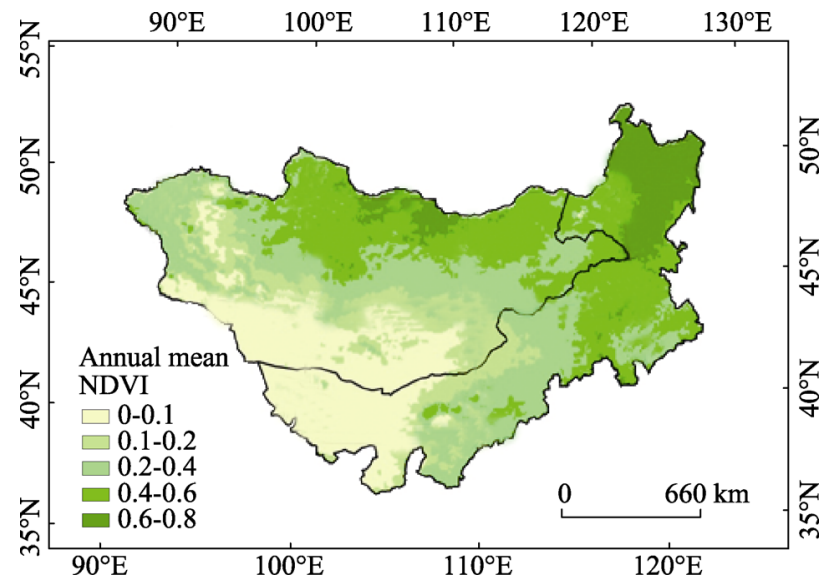

Figure 2 Annual mean NDVI across the Mongolian Plateau from 1982-2013

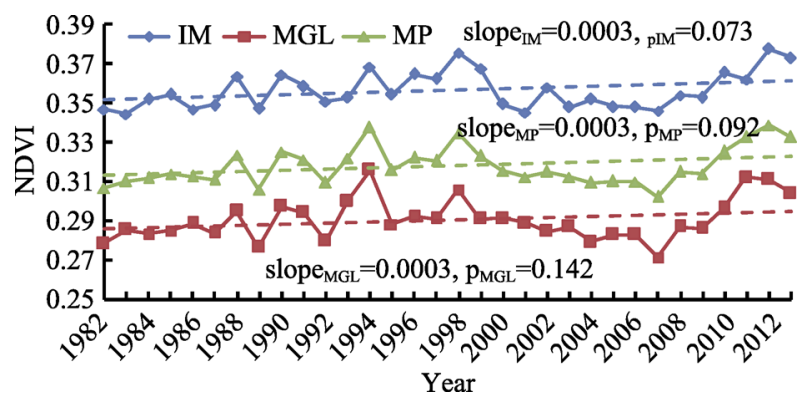

Figure 3 Annual average NDVI values for the Mongolian Plateau (MP), Inner Mongolia (IM), and Mongolia (MGL) from 1982-2003 
there is less heat) the rising temperatures will likely extend the growing season, accelerate the growth rate, increase photosynthesis and water use efficiency, and thus directly enhance vegetation growth (Fang, 2000). During the study period, the inter-annual variability of NDVI in the Mongolian Plateau ranged from 0.3023 (2007) to 0.3387 (2012), with an average value of 0.3179 . For Inner Mongolia, the range was 0.3445 (1983) to 0.3776 (2012), with an average value of 0.3565 , and for the entire plateau the range was 0.2712 (2007) to 0.3159 (1994), with an average value of 0.2904 . The multi-year NDVI average for Inner Mongolia was higher than that for all of Mongolia. The change rates for coniferous forest and cropland were the largest, at 0.0006/yr and 0.0007/yr, respectively. Broadleaf forest and desert both had small change rates, at $0.0002 / \mathrm{yr}$ and $0.0001 / \mathrm{yr}$, respectively (Table 1).

Table 1 Annual average NDVI, slope, and Hurst value for each vegetation type in the Mongolian Plateau from 1982-2013

\begin{tabular}{lcccc}
\hline Vegetation types & NDVI range & NDVI average & Sen's slope/yr & Mean for H \\
\hline Broadleaf forest & $0.59-0.66$ & 0.63 & 0.0002 & 0.419 \\
Coniferous forest & $0.52-0.58$ & 0.56 & 0.0006 & 0.412 \\
Meadow & $0.51-0.56$ & 0.54 & 0.0004 & 0.426 \\
Shrub & $0.43-0.48$ & 0.45 & 0.0005 & 0.447 \\
Cropland & $0.37-0.43$ & 0.39 & 0.0007 & 0.440 \\
Steppe & $0.32-0.39$ & 0.35 & 0.0004 & 0.404 \\
Sandy land & $0.28-0.35$ & 0.31 & 0.0005 & 0.437 \\
Alpine grassland & $0.27-0.31$ & 0.28 & 0.0005 & 0.418 \\
Desert & $0.13-0.16$ & 0.14 & 0.0001 & 0.389 \\
\hline
\end{tabular}

\subsubsection{Spatial variations in NDVI}

Spatial vegetation changes are significantly differentiated through the study area (Figure 4). Increasing trends in NDVI accounted for $67.79 \%$ (about $144.84 \times 10^{4} \mathrm{~km}^{2}$ ) of the total Mongolian Plateau area, with $24.54 \%$ (about $52.45 \times 10^{4} \mathrm{~km}^{2}$ ) showing a significant increase, mainly in the Hetao Irrigation District, Ordos, southern Chifeng, northern Hulunbuir and Khuvsugul, the western edge of Bayan-ulgii, Bulgan, Darkhan-uul, Selenge, Dornot, Sukhbaatar, Sumber,

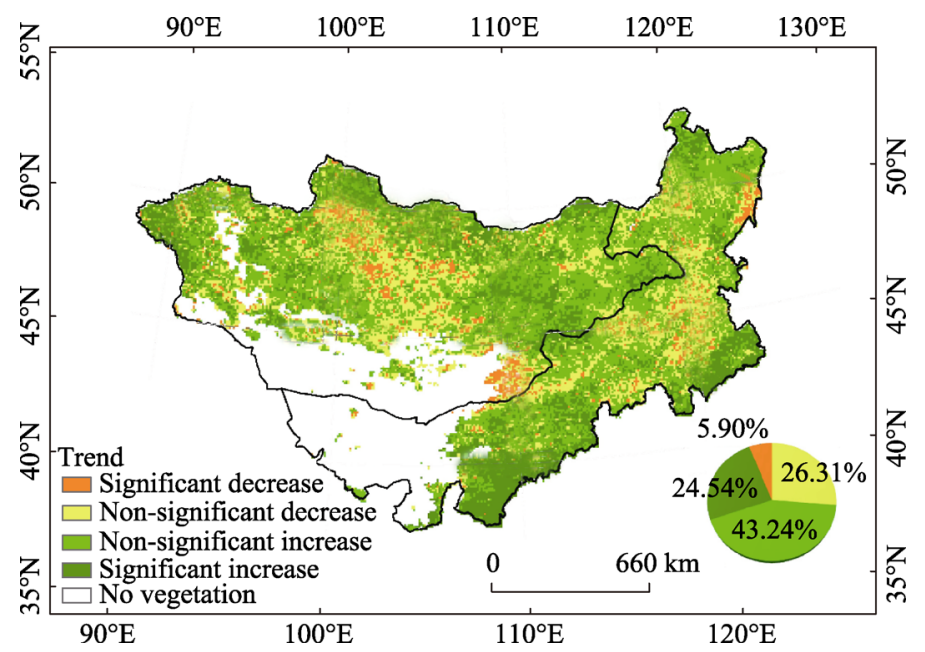

Figure 4 Spatial distribution of NDVI trends on the Mongolian Plateau from1982-2013 
and Khentii in Mongolia. The areas in which NDVI increased significantly were concentrated in the agro-pastoral ecotone, such as the Hetao Irrigation District, Hunshandake, and Horqin Sandy Land in Inner Mongolia, and in middle and low mountainous areas in Mongolia. Another $32.21 \%$ (about $68.84 \times 10^{4} \mathrm{~km}^{2}$ ) of the area showed a decreasing trend in NDVI, of which $5.90 \%$ (about $12.61 \times 10^{4} \mathrm{~km}^{2}$ ) decreased significantly, mainly in Arkhangai, Uvurkhangai, Dundgovi, and Dornogovi in central Mongolia, the transitional zone from steppe to desert areas. A few such pixels were also located at the junction of Xilingol and Chifeng and in eastern Hulunbuir in Inner Mongolia. In general, the NDVI in Inner Mongolia increased significantly, while the NDVI decreased significantly over a larger area of Mongolia. Overall, the NDVI increased over a larger area than that in which it decreased.

\subsection{Analysis of the factors influencing vegetation growth on the Mongolian Plateau}

\subsubsection{Effects of climatic factors on vegetation}

Precipitation and temperature are the main meteorological factors that affect vegetation growth in arid and semi-arid regions. The correlation between NDVI and precipitation or temperature on the Mongolian Plateau is shown in Figures 5 and 6, respectively. NDVI is positively correlated with precipitation over a much larger area than temperature, at $73.19 \%$ $\left(\sim 156.42 \times 10^{4} \mathrm{~km}^{2}\right)$ and $35.25 \%\left(\sim 75.35 \times 10^{4} \mathrm{~km}^{2}\right)$, respectively. This indicates that precipitation is the dominant factor affecting vegetation growth on the Mongolian Plateau and that the inter-annual variability of NDVI is more sensitive to precipitation than to temperature. The area with significant positive correlations between NDVI and precipitation accounted for $24.07 \%$ of the total area and was mainly distributed in the grassland areas of Ordos, Xilingol, Tongliao, and Hulunbuir in Inner Mongolia and Dornot, Dundgovi, Dornogovi, and Arkhangai in Mongolia (Figure 5). The regions showing positive correlation between NDVI and temperature were concentrated in high-latitude areas of the Mongolian Plateau, such as the mountainous region of Mongolia (including Khuvsugul, Bulgan, Darkhan-uul, and Selenge), and the Greater Khingan Range of Inner Mongolia (Figure 6). In addition, NDVI in these regions was negatively correlated with precipitation, indicating that temperature, not precipitation, was the main factor affecting vegetation growth in these high latitude and alpine forest areas.

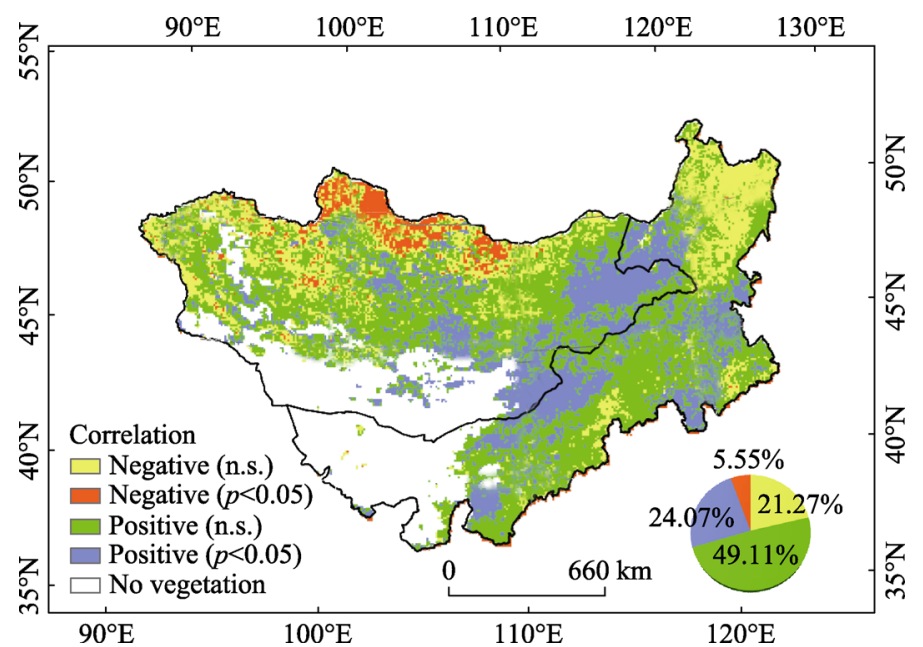

Figure 5 Spatial correlation between NDVI and precipitation from 1982-2013 


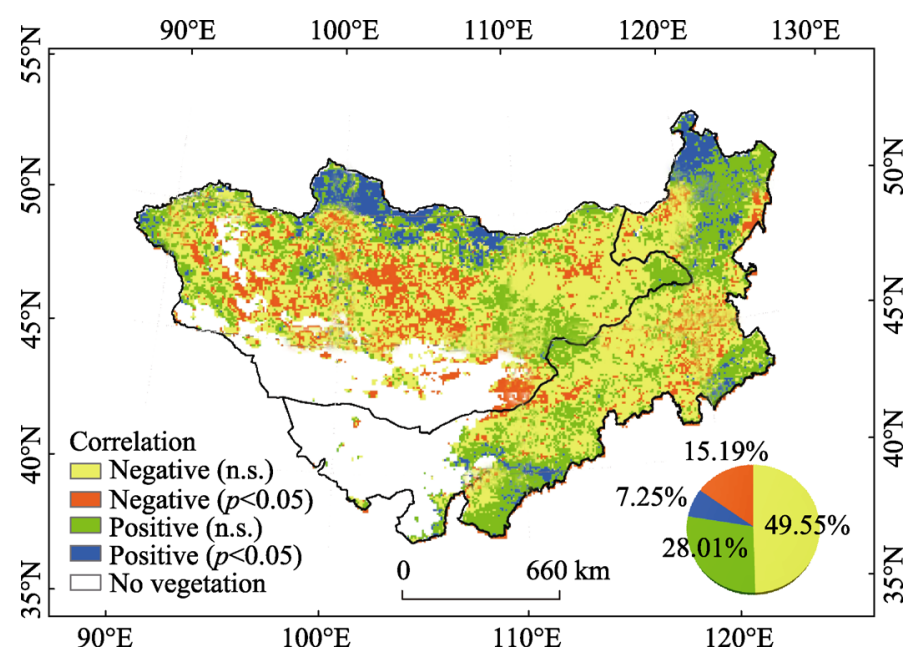

Figure 6 Spatial correlation between NDVI and temperature from 1982-2013

\subsubsection{Effects of human activities on vegetation}

Climate change is an important factor influencing vegetation cover on the Mongolian Plateau, but human activity is also an important driving factor that cannot be neglected. We carried out a residual trend analysis of NDVI to identify and quantify the impact of human activities. First, a linear regression model between NDVI and climatic factors (precipitation and temperature) was constructed, in which climatic factors were the explanatory variables. Using the regression model, existing climate data could be used to predict an annual NDVI value in each grid cell. The predicted NDVI value was then subtracted from the remotely sensed NDVI value to arrive at residual NDVI values from 1982-2013 (Li et al., 2012). Figure 7 shows the spatial distribution of these results. The significantly increased NDVI residuals are mainly concentrated in the Ordos, southern Ulanqab, Chifeng, Tongliao, northwestern Xilingol, and northern Hulunbuir areas of Inner Mongolia and the western Bayan-ulgii, Dornot, western Sukhbaatar, and eastern Dornogovi areas of Mongolia.

The overall significant increase in NDVI residuals indicates that vegetation growth in these areas cannot be explained by climatic factors only. For example, in the Yellow River Basin of Inner Mongolia, which flows through the Ordos and Ulanqab areas, the NDVI change reflects the impact of human activities, which has been shown to depend strongly on irrigation such that there is no dependence on precipitation. Other measures, including the extensive use of chemical fertilizers and pesticides and the construction of irrigation facilities, also influence vegetation cover in the basin (Xin et al., 2008), indicating that human activities play a key role in the increasing vegetation cover.

The NDVI residuals were significantly reduced in the southern part of the Alxa Right Banner, Bayannur, Horqin Sandy Land, Arongqi, Morindavaa, and Oroqen of Hulunbuir areas in Inner Mongolia (Figure 7), indicating that vegetation growth in these areas is lagging behind the growth predicted by climate. One hypothesis for this trend is that human activities are leading to land degradation, resulting in a reduction in NDVI. For example, deterioration of ecosystems, serious land desertification, and arable land reduction since the 1950s has forced a large number of farmers to relocate to the southern part of Alxa Right Banner, adjacent to Minqin County in Gansu Province. They began collecting herbs and 
wild plants from the sandy soil, so that the ecological environment has become more fragile, with surface vegetation suffering serious damage. Another example can be found in the degradation of Horqin Sandy Land, where the development and subsequent abandonment of large areas of wasteland has led not only to reduction in grassland, but also to increased soil erosion. Overgrazing also causes land degradation in this area (Jiang et al., 2004).

In other regions, the role of human activities in increasing or decreasing NDVI still requires further validation. However, based on analysis of the Yellow River Basin, Alxa Right Banner, and Horqin Sandy Land, we assume that if the NDVI residual trend is positive, human activities must have played a large role in increasing NDVI, while a negative slope indicates that human activities had a destructive effect. The area of significantly increasing residual trend occupied $26.14 \%$ (about $39.35 \times 10^{4} \mathrm{~km}^{2}$ ) of the total study area $(9.50 \%$ in Mongolia, $16.64 \%$ in Inner Mongolia), while the area of significantly decreasing residual occupied only $3.77 \%$ (about $7.94 \times 10^{4} \mathrm{~km}^{2}$ ), indicating that human activity had a net positive effect on NDVI. Moreover, the population of Mongolia is smaller, one-tenth that of Inner Mongolia. Additionally, the state is currently following an official ecological policy, so the intensity of human activity in Mongolia is weaker than that in Inner Mongolia.

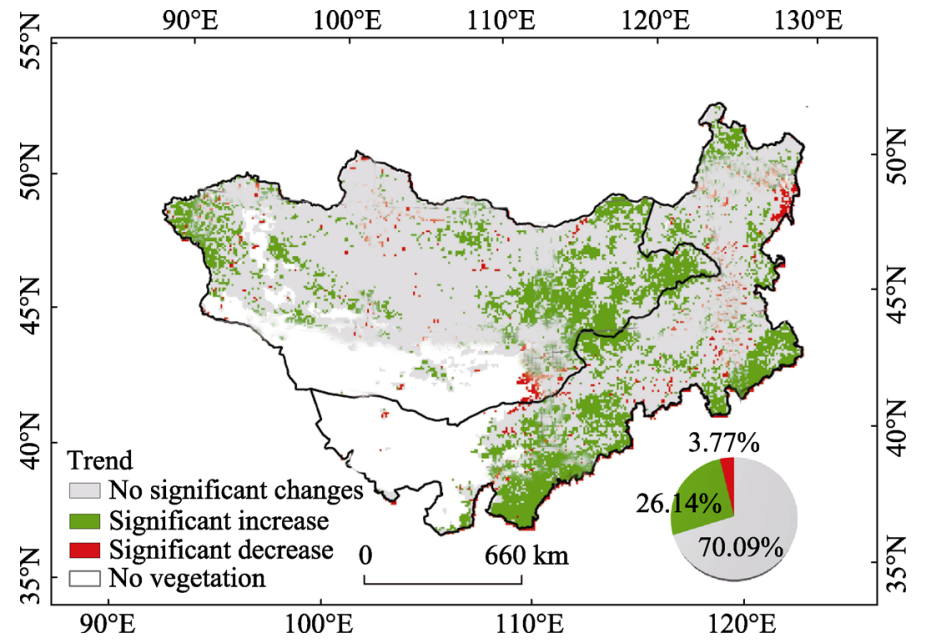

Figure 7 Spatial distribution of residual NDVI trends on the Mongolian Plateau from 1982-2013

\subsection{Future vegetation dynamic trends based on the Hurst exponent}

Figure 8 shows the spatial distribution of the Hurst exponents for the NDVI time-series. Using $\mathrm{H}=0.5$ as the threshold value, the predicted trend of vegetation change can be divided into three categories: $\mathrm{H}=0.5$ indicates that there will not be significant changes in future NDVI, $\mathrm{H}>0.5$ indicates that future NDVI trends will remain consistent with current trends, and $\mathrm{H}<0.5$ indicates that future NDVI trends will reverse from current trends. NDVI trends expected to remain consistent with the current state accounting for $12.05 \%$ (about $25.75 \times 10^{4}$ $\mathrm{km}^{2}$ ) of the total area of the Mongolian Plateau, while $87.95 \%$ (about $187.97 \times 10^{4} \mathrm{~km}^{2}$ ) of the area is predicted to see a reverse in the current NDVI trends. The Hurst exponent value was lower around the border between the two countries and relatively high in other regions. The region with $\mathrm{H}>0.5$ was mainly concentrated in Ordos and the southern part of Chifeng in Inner Mongolia (Figure 8). The Hurst exponent is closely related to vegetation cover, with high $\mathrm{H}$ values for lush vegetation and low $\mathrm{H}$ values for sparsely vegetated land. 


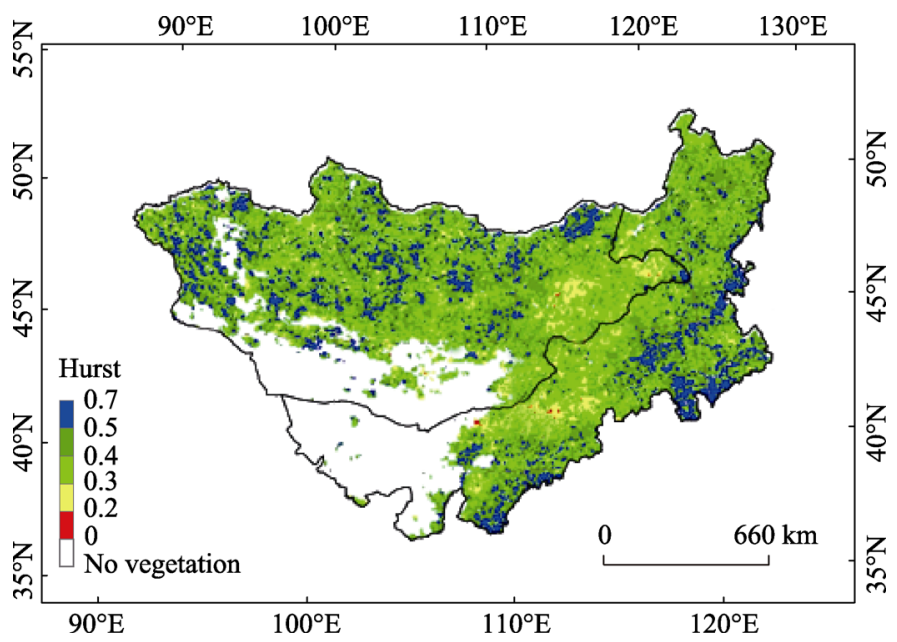

Figure 8 Spatial distribution of the Hurst exponent for the annual average NDVI time series on the Mongolian Plateau from 1982-2013. Values over 0.5 suggest a continuation in the past trend, while values below 0.5 suggest a reversal in the past trend

The MK test quantitatively identifies trends in NDVI over a given time period, while the $\mathrm{R} / \mathrm{S}$ analysis qualitatively identifies whether future trends were predicted to continue in the same direction or switch to the opposite direction. However, neither approach indicates whether an increasing or decreasing trend can be expected in the future. By combining results from the two analyses, reasonable predictions of future trends in vegetation changes can be made (Table 2 and Figure 9). We set 0.05 as the significance level, and used $20>|\mathrm{Zc}|>1.96$ as the reference range for significant increases or decreases. A value of $\mathrm{H}=0.5$ was used as a criterion to judge whether the change in NDVI would continue in same direction. "Improvement" indicates that NDVI has been decreasing, but will increase in the future. "Degradation" indicates that NDVI has been increasing, but will decrease in the future.

Table 2 Parameters for predicted future vegetation change trends

\begin{tabular}{lll}
\hline & \multicolumn{1}{c}{$-20<\mathrm{Zc}<-1.96$} & \multicolumn{1}{c}{$1.96<\mathrm{Zc}<20$} \\
\hline $\mathrm{H}<0.5$ & Improvement & Degradation \\
$\mathrm{H}>0.5$ & Consistent degradation & Consistent improvement \\
\hline
\end{tabular}

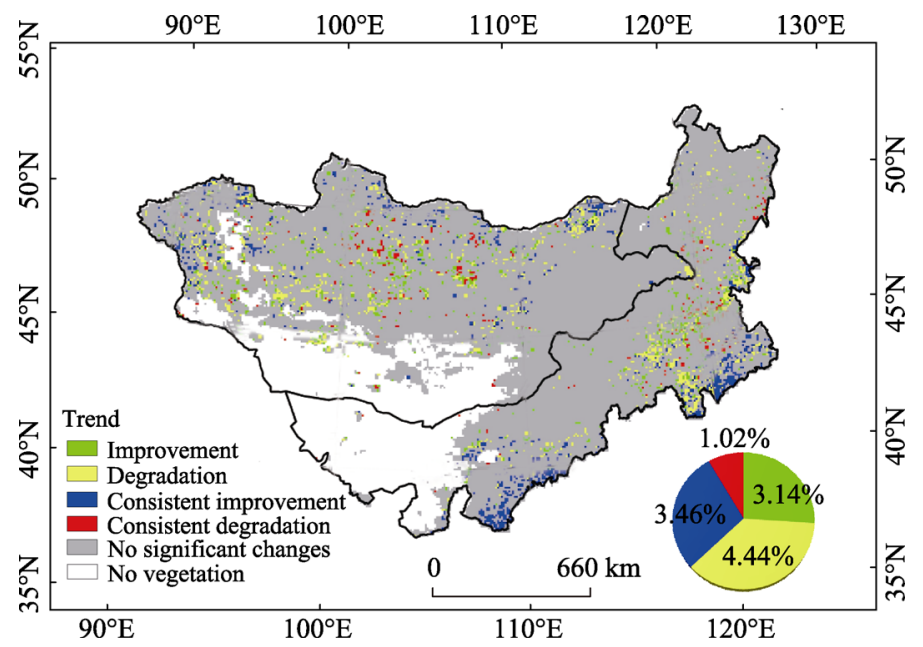

Figure 9 Predicted vegetation changing trends on the Mongolian Plateau 
"Consistent improvement" or "Consistent degradation" indicates that the NDVI changes will continue in the same direction as before.

The results suggest that there will be more improved area than degraded area in the future; the degradation area accounted for $5.46 \%$ (about $11.65 \times 10^{4} \mathrm{~km}^{2}$ ) and the improvement area $6.60 \%$ (about $14.10 \times 10^{4} \mathrm{~km}^{2}$ ) of the total plateau (Figure 9). The degradation area accounted for $4.44 \%$ of the study area, mainly in south-central Xilingol of Inner Mongolia and central Mongolia. The improvement area accounted for $3.14 \%$ of the study area, but was scattered throughout the region. The areas of consistent improvement accounted for $3.46 \%$ of the study area. Most of these areas implemented large-scale desertification control and ecological management projects during the study period, as was the case in Horqin Sandy Land and Ordos (Ma et al., 2015; Li et al., 2006). In general, the vegetation of the Mongolian Plateau is not expected to change significantly in the future, as significant values were found for only about $13 \%$ of the area. The improvement area is larger than the degradation area, and the greatest vegetation improvement occurred in Ordos and Tongliao in Inner Mongolia. The reasons for these observed changes involved both natural and human factors, as discussed below.

\section{Discussion}

From the above analysis, we can conclude that precipitation is the most important factor affecting vegetation growth on the Mongolian Plateau. However, precipitation has substantially decreased and temperatures have significantly increased over the past 32 years, causing significant aridity. In this region, the precipitation rate gradually increases from south to north. Precipitation has decreased in most regions (excepting the desert regions of the southwestern plateau), with the precipitation reduction in Mongolia being larger than that in Inner Mongolia (Figure 10a). Conversely, temperatures increased across the entire plateau, with the largest increases occurring in the central plateau (Figure 10b). In general, the climate of the Mongolian Plateau has become drier (Figure 10c). The degree of drought in Mongolia is higher than that in Inner Mongolia, and human activities are more apparent in Inner Mongolia, which may be the cause of the better vegetation growth in Inner Mongolia than in Mongolia.

On the other hand, agriculture and animal husbandry is the main economic base of the Mongolian Plateau, with $26.2 \%$ of the gross national product for Mongolia coming from agriculture and animal husbandry, of which $80 \%$ comes from nomadic animal husbandry (Zhen et al., 2008). Animal husbandry in Inner Mongolia has shifted from nomadic to settled villages. At the beginning of the 21 st century, the government implemented ecological protection and vegetation restoration projects, including Three-North Shelterbelt, Grain for Green, Beijing and Tianjin Sandstorm Source Control, and Establishment of a Nature Reserve, to protect and improve the ecological environment, and ensure sustainable development of animal husbandry. These programs have achieved many beneficial results.

In Ordos and Tongliao of Inner Mongolia, the number of livestock has increased annually since 2000 (Figure 11). Excessive grazing of livestock reduces grass height, which decreases NDVI and leads to different degrees of surface exposure (Guo, 2007). However, the cumulative afforested areas have consistently increased since the implementation of ecological restoration projects with the result that vegetation in these two regions has increased significantly. 


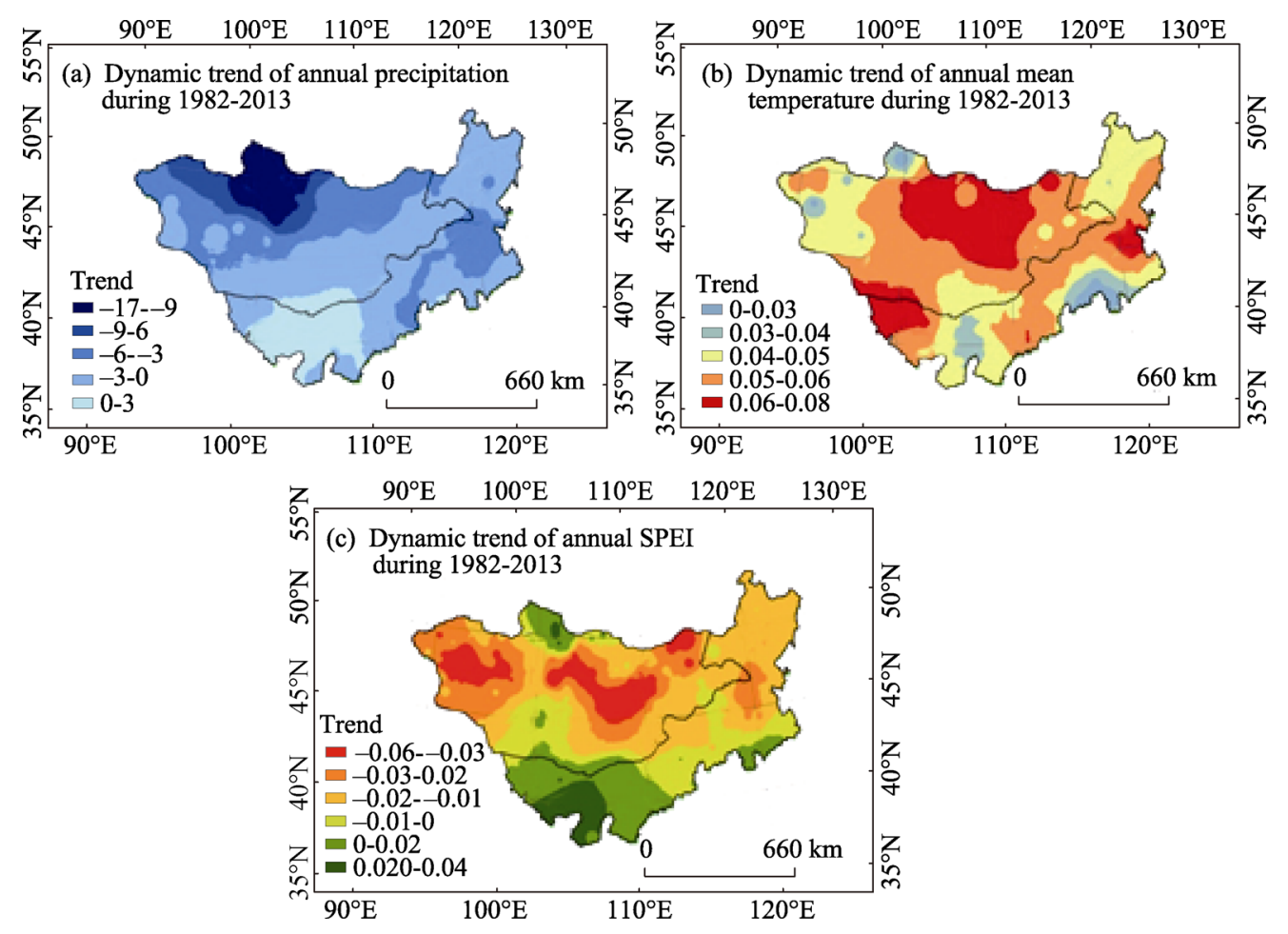

Figure 10 Dynamic trends of precipitation (a), temperature (b), and Standardized Precipitation Evapotranspiration Index (SPEI) (c) on the Mongolian Plateau from1982-2013

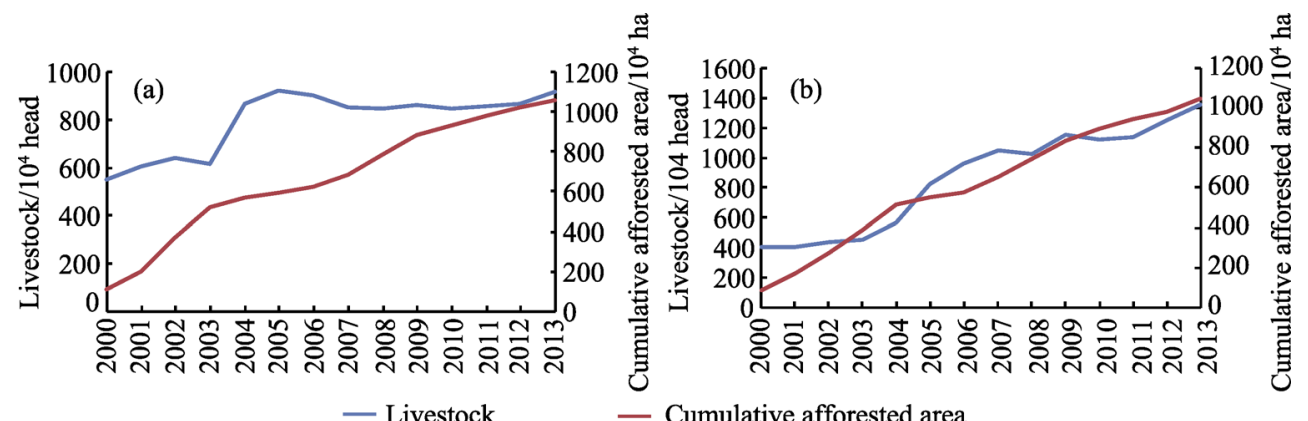

Figure 11 Statistics for livestock numbers and cumulative afforested area in Ordos (a) and Tongliao (b), Inner Mongolia, from 2000-2013

This explanation supports the use of residual trend analysis for studying the impact of human activity on NDVI, and this conclusion was consistent with the result of Li et al. (2014). In addition, the Forestry Law, which was enacted in 1945, has reduced forest disease and fire disasters and increased the vegetation cover in the study area (Zhou et al., 2012). Measures such as fence-blocked grazing, prohibition of deforestation, popularization of anti-wind erosion devices, and improved cultivation techniques have also played a key role in the increased NDVI (Liu et al., 2005).

We used the Hurst exponent to predict the future vegetation trend on the Mongolian Plateau. This provides a new approach to the study of vegetation and has been widely used to analyze the consistency of future vegetation trends in recent years with effective results (Peng et al., 2012; Liu et al., 2015; Liu et al., 2016). Compared with previous studies on vegetation dynamics, 
it considers whether the future trend in vegetation is consistent with current state. However, the proposed R/S analysis with the Hurst exponent could not determine how long the anticipated vegetation trend would continue in the future. Therefore, it is important for future research to focus on extending the time span for which future vegetation dynamics can be forecasted.

The Mongolian Plateau is an important ecological boundary for China, playing a significant role in the country's ecological environment. As an important part of the East Asian ecosystem it plays important role in the global carbon cycle (Lu et al., 2009). Because of its special geographical location, it is important to study vegetation changes in this region in the context of global climate change. As vegetation dynamics in the plateau result from climate change and human activities, our results demonstrate that these methods can provide a theoretical basis for the development of rational measures to protect the vegetation environment in the future.

\section{Conclusions}

(1) From 1982-2013, NDVI showed an upward tendency with a rate of $0.0003 / \mathrm{yr}$ in the Mongolian Plateau. Vegetation growth in Inner Mongolia was better than that in Mongolia, with an annual average value of 0.0066 .

(2) The area of increasing NDVI on the Mongolian Plateau was much larger than that of decreasing NDVI, at $67.79 \%\left(\sim 144.84 \times 10^{4} \mathrm{~km}^{2}\right)$ and $32.21 \%\left(\sim 68.84 \times 10^{4} \mathrm{~km}^{2}\right)$ of the total plateau area, respectively. The areas of significant increase and decrease accounted for $24.54 \%$ and $5.90 \%$ of the total area, respectively. Areas with a significant increase in NDVI were located mainly in Ordos and Tongliao in the agro-pastoral ecotone of Inner Mongolia, along the southern part of the plateau. Areas with significant decreasing trends were distributed in central Mongolia and parts of Chifeng, southeast Xilingol, and eastern Hulunbuir in Inner Mongolia.

(3) From the Hurst exponent analysis, we concluded that the predicted vegetation growth would remain consistent with previous trends in $12.05 \%$ (about $25.75 \times 10^{4} \mathrm{~km}^{2}$ ) of the total area, while the other $87.95 \%$ (about $187.97 \times 10^{4} \mathrm{~km}^{2}$ ) was predicted to reverse trends. The Hurst exponent was closely related to the vegetation cover, with high values in lush vegetation and low values in sparse vegetation. The predicted vegetation trends for the Mongolian Plateau were not significant in most of the area, with only about $13 \%$ of the vegetation showing significant trends. The predicted improvement area was larger than the predicted degradation area.

(4) The area with positive correlations between NDVI and precipitation $(73.19 \%$, $\sim 156.42 \times 10^{4} \mathrm{~km}^{2}$ ) was much larger than that with positive correlations between NDVI and temperature $\left(35.25 \%, \sim 75.35 \times 10^{4} \mathrm{~km}^{2}\right)$, indicating that precipitation is the dominant climate factor for vegetation growth in the plateau. The significantly increased area of NDVI residuals occupied $26.14 \%\left(\sim 39.35 \times 10^{4} \mathrm{~km}^{2}\right)$ of the total area of the Mongolian Plateau, while the significantly decreased area was only $3.77 \%\left(\sim 7.94 \times 10^{4} \mathrm{~km}^{2}\right)$, indicating that the human influence on vegetation cover was positive for most of the Mongolian Plateau. The intensity of human activity in Mongolia was weaker than that in Inner Mongolia.

\section{References}

Chang Z, Gong H, Zhang J et al., 2014. Correlation analysis on interferometric coherence degree and probability of residue occurrence in interferogram. Sensors Journal IEEE, 14(7): 2369-2375. 
Fang J Y, 2000. Forest biomass carbon pool of middle and high latitudes in the north hemisphere is probably much smaller than present estimates. Acta Phytoecologica Sinica, 24 (5): 635-638. (in Chinese)

Fensholt R, Langanke T, Rasmussen K et al., 2012. Greenness in semi-arid areas across the globe 1981-2007: An earth observing satellite based analysis of trends and drivers. Remote Sensing of Environment, 121: 144-158.

Granero M A S, Segovia J E T, Pérez J G, 2008. Some comments on Hurst exponent and the long memory processes on capital markets. Physica A Statistical Mechanics and Its Applications, 387(22): 5543-5551.

Guo X J, 2007. Relationship between grazing intensity with vegetation structure and grassland ecological environment. Qinghai Prataculture, 16(2): 17-20. (in Chinese)

Holben B N, 1986. Characteristics of maximum-value composite images from temporal AVHRR data. International Journal of Remote Sensing, 7(11): 435-445.

Hulme M, Doherty R, Ngara T et al., 2001. African climate change: 1900-2100. Climate Research, 17(2): $145-168$.

Hurst H E, 1951. Long term storage capacity of reservoirs. Transactions of the American Society of Civil Engineers, 116(12): 776-808.

Ichii K, Kawabata A, Yamaguchi Y, 2002. Global correlation analysis for NDVI and climatic variables and NDVI trends: 1982-1990. International Journal of Remote Sensing, 23(18): 3873-3878.

Jiang D M, Liu Z M, Kou Z W et al., 2004. Ecological environment and its sustainable management of Horqin steppe: A report on the survey of Horqin sandy land. Chinese Journal of Ecology, 23(5): 179-185. (in Chinese)

John R, Chen J, Ouyang Z et al., 2013. Vegetation response to extreme climate events on the Mongolian Plateau from 2000-2010. Environmental Research Letters, 8, 035033 (12pp).

Jong R D, Bruin S D, Wit A D et al., 2011. Analysis of monotonic greening and browning trends from global NDVI time-series. Remote Sensing of Environment, 115(2): 692-702.

Kendall M, 1975. Rank Correlation Methods. London: Charles Griffin.

Lambin E F, Strahler A H, 1994. Indicators of land-cover change for change-vector analysis in multitemporal space at coarse spatial scales. International Journal of Remote Sensing, 15(10): 2099-2119.

Li A, Wu J G, Huang J H, 2012. Distinguishing between human-induced and climate-driver vegetation changes: A critical application of RESTREND in Inner Mongolia. Landscape Ecology, 27: 969-982.

Li A M, Han Z W, Xu J et al., 2006. Transformation dynamics of desertification in Horqin sandy land at the beginning of the 21st century. Acta Geographica Sinica, 61(9): 976-984. (in Chinese)

Li J Y, Chen P Q, Ma Z G et al., 2006. Regional research: A main approach to understanding the global environmental change. Advances in Earth Science, 21(5): 441-450. (in Chinese)

Li W Y, Qian Z A, An M H et al., 2006. Temporal and spatial feature analyses of winter and summer surface air temperature over CMASA, part ( II ): July. Plateau Meteorology, 25(4): 624-632. (in Chinese)

Li X G, Liu H M, Wang L X et al., 2014. Vegetation cover change and its relationship between climate and human activities in Ordos plateau. Chinese Journal of Agrometeorology, 35(4): 470-476. (in Chinese)

Li X Z, Liu X D, 2012. A modeling study on drought trend in the Sino-Mongolian arid and semiarid regions in the 21 st century. Arid Zone Research, 29(2): 262-272. (in Chinese)

Liu X, Pan Y, Zhu X et al., 2015. Spatiotemporal variation of vegetation coverage in Qinling-Daba Mountains in relation to environmental factors. Acta Geographica Sinica, 70(5): 705-716. (in Chinese)

Liu Y, Li C Z, Liu Z H et al., 2016. Assessment of spatio-temporal variations in vegetation cover in Xinjiang from 1982 to 2013 based on GIMMS-NDVI. Acta Ecologica Sinica, 36(19): 1-11. (in Chinese)

Liu Y L, Pan Z H, Fan J L et al., 2005. Spatial and temporal analyses on vegetation cover dynamics in north piedmont of Yinshan Mountain. Resources Science, 27(4): 168-174. (in Chinese)

Liu Z, Notaro M, Kutzbach $\mathrm{J}$ et al., 2006. Assessing global vegetation-climate feedbacks from observations. Journal of Climate, 19(5): 787-814.

Lu Y, Zhuang Q, Zhou G et al., 2009. Possible decline of the carbon sink in the Mongolian Plateau during the 21st century. Environmental Research Letters, 4(4): 940-941.

Ma W Y, He L, Zhao C Y, 2015. Desertification dynamics in Alxa League over the period of 2000-2012. Journal of Lanzhou University, 51(1): 55-60, 71. (in Chinese)

Miao L J, Liu Q, Fraser R et al., 2015. Shifts in vegetation growth in response to multiple factors on the Mongolian Plateau from 1982 to 2011. Physics and Chemistry of the Earth Parts A/B/C, 87-88, 50-59.

Myneni R B, Keeling C D, Tucker C J et al., 1997. Increased plant growth in the northern high latitudes from 1981 to 1991. Nature, 386(6626): 698-702. 
Nemani R R., Keeling C D, Hashimoto H et al., 2003. Climate-driven increases in global terrestrial net primary production from 1982 to 1999. Science, 300(5625): 1560-3.

Park H S, Sohn B J, 2010. Recent trends in changes of vegetation over East Asia coupled with temperature and rainfall variations. Journal of Geophysical Research Atmospheres, 115(D14): 1307-1314.

Parry M L, Canziani O F, Palutikof J P et al., 2007. IPCC Fourth Assessment Report: Climate Change, 1340-1356.

Peng J, Liu Z, Liu Y et al., 2012. Trend analysis of vegetation dynamics in Qinghai-Tibet Plateau using Hurst exponent. Ecological Indicators, 14(1): 28-39.

Piao S L, Mohammat A, Fang J Y et al., 2006. NDVI-based increase in growth of temperate grasslands and its responses to climate changes in China. Global Environmental Change, 16(4): 340-348.

Seager R, Ting M, Held I et al., 2007. Model projections of an imminent transition to a more arid climate in southwestern North America. Science, 316(5828): 1181-1184.

Sen P K, 1968. Estimates of the regression coefficient based on Kendall's tau. Journal of the American Statistical Association, 63(324): 1379-1389.

Song Y, Ma M G, 2011. A statistical analysis of the relationship between climatic factors and the normalized difference vegetation index in China. International Journal of Remote Sensing, 45(14): 374-82.

Tošić I, 2004. Spatial and temporal variability of winter and summer precipitation over Serbia and Montenegro. Theoretical and Applied Climatology, 77(1): 47-56.

Wang L, Zhen L, Liu X L et al., 2008. Comparative studies on climate changes and influencing factors in central Mongolian Plateau region. Geographical Research, 27(1): 171-180. (in Chinese)

Wei Y J, Zhen L, Ochirbat B et al., 2009. Empirical study on consumption of ecosystem services and its spatial differences over Mongolian Plateau. Resources Science, 31(10): 1677-1684. (in Chinese)

Wessels K J, Prince S D, Malherbe J et al., 2007. Can human-induced land degradation be distinguished from the effects of rainfall variability? A case study in South Africa. Journal of Arid Environments, 68(2): 271-297.

Whetton P H, Fowler A M, Haylock M R et al., 1993. Implications of climate change due to the enhanced greenhouse effect on floods and droughts in Australia. Climatic Change, 25(3): 289-317.

Xin Z B, Xu J X, Zheng W, 2008. Spatiotemporal variations of vegetation cover on the Chinese Loess Plateau (1981-2006): Impacts of climate changes and human activities. Science China Earth Sciences, 51(1): 67-78. (in Chinese)

Yatagai A, Yasunari T, 1995. Interannual variations of summer precipitation in the arid/semi-arid regions in China and Mongolia: Their regionality and relation to the Asian summer monsoon. Journal of the Meteorological Society of Japan, 73(5): 909-923.

Zhang X Y, Hu Y F, Zhuang D F et al., 2009. NDVI spatial pattern and its differentiation on the Mongolian Plateau. Journal of Geographical Sciences, 19(4): 403-415.

Zhao X, Hu H F, Shen H H et al., 2015. Satellite-indicated long-term vegetation changes and their drivers on the Mongolian Plateau. Landscape Ecology, 30(9): 1599-1611.

Zhao Y X, Qiu, G W, 2001. Study of climate change impact on northern farming-pastoral region. Meteorological Monthly, 27(5): 3-7. (in Chinese)

Zhao Z C, Wang S W, Luo Y, 2007. Assessments and projections of temperature rising since the establishment of IPCC. Advances in Climate Change Research, 3(3): 83-84. (in Chinese)

Zhen L, Liu J Y, Liu X L et al., 2008. Structural change of agriculture-livestock system and affecting factors in Mongolian Plateau. Journal of Arid Land Resources and Environment, 22(1): 144-151. (in Chinese)

Zhou L M, Kaufmann R K, TianY et al., 2003. Relation between interannual variations in satellite measures of northern forest greenness and climate between 1982 and 1999. Journal of Geophysical Research Atmospheres, 108(D1): ACL 3-16.

Zhou L M, Tucker C J, Kaufmann R K et al., 2001. Variations in northern vegetation activity inferred from satellite data of vegetation index during 1981 to 1999. Journal of Geophysical Research Atmospheres, 106(D17): 20069-20084.

Zhou X Y, Shi H D, Wang X R et al., 2012. Study on the temporal and spatial dynamic changes of land use and driving forces analysis of Mongolia Plateau in recent 30 years. Acta Agriculture Zhejiangensis, 24(6): 1102-1110. (in Chinese)

Zhuo Y, 2007. The ration remote sensing method study of desertification of Mongolian Plateau based on MODIS data [D]. Huhhot: Inner Mongolia Normal University, 1-51. (in Chinese) 